\title{
Correction to: COVID-19: The crucial role of blood coagulation and fibrinolysis
}

\author{
Sergio Coccheri ${ }^{1}$
}

Published online: 22 October 2020

(c) Società Italiana di Medicina Interna (SIMI) 2020

\section{Correction to: Internal and Emergency Medicine https://doi.org/10.1007/s11739-020-02443-8}

In the original publication of the article, the sentence under the heading "Coagulation" that reads as "This peculiar coagulation ... DIC the marked elevation of D-dimer levels" has been incorrectly published.

According to the original version of the article the right wording should be as follows:

"This peculiar coagulation activation was initially perceived as a close variant of Disseminated Intravascular Coagulation (DIC) $[8,9]$ but is presently seen as substantially distinct from DIC. In fact, although the microthrombotic syndrome shares with DIC the marked elevation of D-dimer levels,..."

Publisher's Note Springer Nature remains neutral with regard to jurisdictional claims in published maps and institutional affiliations.

The original article can be found online at https://doi.org/10.1007/ s11739-020-02443-8.

Sergio Coccheri

coccheris.angio@libero.it

1 University of Bologna, Bologna, Italy 